\title{
Bailando con árbol. Visibilizando las protoacciones naturales de la vanguardia artística española
}

\section{Dancing with a tree. Visibilizing the natural protoactions of the Spanish artistic avant-garde}

\author{
TIPO DE TRABAJO: Comunicación.
}

PALABRAS CLAVE

Arte de acción, protoperformance, vanguardias españolas, naturaleza vegetal.

KEY WORDS

Action art, protoperformance, Spanish avant-garde, plant nature.

RESUMEN

La investigación que aquí se presenta permite visibilizar la conexión creativa que existía entre los artistas, músicos, bailarines y escritores de la vanguardia española con ciertos elementos de la naturaleza vegetal, develando el origen de los vínculos de estas relaciones, a través de las acciones inspiradoras que llevaban a cabo de forma muy innovadora. El texto tiene entre sus objetivos el de poner de manifiesto la interacción de estos creadores, con ciertos elementos procedentes del mundo vegetal, como recurso inspirador dentro de los procesos artísticos. Su utilización, en el contexto de las vanguardias artísticas, va más allá de la realidad misma de la naturaleza vegetal, así como de las propias disciplinas artísticas empleadas, explorando y trasgrediendo en España durante las primeras décadas del siglo XX- los límites habituales del arte. Este tipo de propuestas de acción, en algunas ocasiones únicamente poéticas y en otras ocasiones políticas, pueden considerarse antecedentes del performance, por lo que las hacemos visibles partiendo del concepto de protoperformance. Tradicionalmente la Naturaleza ha sido la gran maestra de las formas, no sólo en lo que se refiere a la vertiente matérico-orgánica de las creaciones artísticas, sino también en el mundo de la simbología y de la ficción. Su empleo en el ámbito artístico remite a conceptos vitales como crecimiento, multiplicación, dispersión, semejanza, muchos de los cuales, fueron rescatados por los artistas de la época en la que se centra este texto, para despertar una nueva conciencia del ser humano frente al mundo.

\section{ABSTRACT}

The present investigation allows to visualize the creative connection that existed between the artists, musicians, dancers and writers of the Spanish vanguard with certain elements of the vegetal nature. The origin of the links of these relationships is revealed, through the inspiring actions carried out in a very innovative way. The text has among its objectives to highlight the interaction of these creators, with certain elements from the plant world, as an inspiring resource within the artistic processes. Its use, in the context of the artistic avant-garde, goes beyond the very reality of plant nature, as well as of the artistic disciplines employed, exploring and transgressing in Spain -during the first decades of the 20th century- the usual limits of the art. This type of action proposals, sometimes only poetic and on other political occasions, can be considered as a performance background, and they become visible starting from the concept of protoperformance. Traditionally, Nature has been the great teacher of forms, not only in regard to the material-organic aspect of artistic creations, but also in the world of symbolism and fiction. Its use in the artistic field refers to vital concepts such as growth, multiplication, dispersion, similarity, many of which were rescued by the artists of those years, to awaken a new awareness of the human being in front of the world. 


\section{INTRODUCCIÓN}

El carácter transgresor de los artistas de la vanguardia española y su nueva relación con la naturaleza se manifiesta a través de propositivas acciones. Esta investigación permite visualizar algunas de las acciones que los artistas, músicos, bailarines, poetas y escritores de la vanguardia española realizaban de manera espontánea, interactuando con elementos de la naturaleza. El carácter innovador de estas manifestaciones, no han sido analizado suficientemente al ser consideradas como locuras pasajeras. Sin embargo, desde el punto de vista del performance contemporáneo, estas actitudes y registros artísticos son antecesores de esta disciplina y suponen un punto de partida del vínculo entre los creadores y su concepción de la naturaleza, expresado a través de la acción. La interacción con el medio natural y el empleo de elementos sencillos y naturales, en el contexto de las vanguardias artísticas, va más allá de la realidad misma. De hecho, la misma diversidad de las disciplinas artísticas empleadas da cuenta de la necesidad de estos artistas de explorar nuevos lenguajes y de experimentar con materiales alternativos. Todo ello es reflejo de una nueva conciencia, de un deseo de naturalidad que transmiten las acciones, trasgrediendo de esta forma en España -durante las primeras décadas del siglo XX- los límites habituales del arte. Este tipo de acciones poéticas, sociales o políticas inscritas en la cotidianidad y en ocasiones, transgresoras de la misma, pueden considerarse antecedentes del performance, por lo que las hacemos visibles a través del concepto de "protoperformances".

\section{METODOLOGÍA}

El prefijo de origen griego "proto" se utiliza en la formación de nombres y adjetivos con el sentido de "primero". Con la intención de aportar información sobre acciones relacionadas con la naturaleza, en el contexto de las vanguardias artísticas y literarias españolas, se ha recopilado documentación sobre diferentes creadores cuyos actos de carácter espontáneo o relacionados con un uso de materiales procedentes de la naturaleza pueden considerarse antecedentes del performance contemporáneo. Se han recopilado acciones de Maruja Mallo, Miguel Hernández, Vicente Escudero, Vitín Cortezo, Gregorio Prieto, Carmen Barradas, Tórtola Valencia y Emilio Varela.

\section{DESARROLLO}

\section{Maruja Mallo: vestida de espigas y algas}

Maruja Mallo (1902-1995), pintora surrealista cercana a la Generación del 27 se inició junto a García Lorca, Gómez de la Serna, Buñuel, Alberti y Dalí en la Cofradía de la Perdiz, en lo que se puede denominar los albores del arte de acción o protoperformance española. Estas reuniones se llevaban a cabo en la Residencia de Estudiantes en Madrid (Soler, 1980). Lorca disponía en su habitación de un armario en el que ponía un frutero lleno de limones y azucarillos y, a manera de ritual de iniciación, a cada nuevo miembro de la Cofradía le daba un limón rociado con azucarillos, anunciándole así su nueva pertenencia a dicha cofradía. Maruja Mallo apostó por la frescura creativa de los nuevos lenguajes. Cuando estalló la Guerra Civil, viajó a Uruguay y Argentina para dar una serie de conferencias auspiciadas por la Asociación de Amigos del Arte (Pérez de Ayala, 2009, p. 20). Entre las acciones o improvisaciones que podemos considerar como protoperformances vanguardistas (Molina, 15 de noviembre de 2007) destaca, cuando en 1933 Mallo se dirigía en bicicleta a dar sus clases en Arévalo:

[...] decidió entrar en la misa de doce de la iglesia mayor de Arévalo montada en bicicleta, enfilar la nave central, rodear con garbo ciclista el altar mayor y salir del templo a velocidad de crucero mientras las beatas sumergían las cabezas en la pila del agua bendita ante el advenimiento con faldas del demonio (Lucas, 2 de marzo de 2015).

Las primeras obras de Maruja Mallo tenían un fuerte componente de naturaleza. Las pinturas más liberadoras de la artista surgieron en la Pradera de San Isidro, en las romerías a las que asistían los artistas de la época para percibir la vida como una celebración del campo (Ramón Gómez de la Serna, 1942, p. 9). Cuando Mallo vuelve a Madrid en 1935, le encargan la escenografía y los figurines para el ballet moderno Clavileño, de Rodolfo Halffter. En la puesta en escena, Mallo se decanta por emplear elementos vegetales naturales (Fig. 1). Al sembrar la escena de trigo y cebada rescata también el componente sonoro: el sonido de la paja crujiente o "el canto de las espigas" (Gómez de la Serna, 1942, p. 14). El interés de Maruja Mallo por los elementos naturales tiene un fuerte componente de arte de acción. Así lo demuestran las imágenes de la propia artista con algas (Fig. 2) en la Isla de Pascua (Chile). En estos parajes y, con la ayuda de su amigo Pablo Neruda, la artista se fotografía,

[...] a modo de foto-acciones toda ella envuelta de algas de cinco a veinte metros de largas por todo su cuerpo, como diosa de la profundidad del mismo océano Pacífico, siendo para ella las algas "el futuro alimento de la humanidad". Esta forma de intervenir sobre su propio cuerpo con elementos orgánicos, como si de un vestido se tratara, anticipa los trabajos de muchas artistas mujeres posteriores, como los realizados en los años setenta con elementos vegetales por Ana Mendieta [...] (Molina, 2007). 
Los artistas que emplean elementos naturales en su obra establecen una relación con lo trascendente a través del mito y la creencia en un orden cósmico. Aquí la producción de imagen tiene que ver con la "identificación del artista con el entorno natural y en estos casos, el cuerpo físico del artista es considerado uno y lo mismo con la naturaleza, evidenciando así el vínculo arte-vida" (Abarca, 2012, p. 16). Estas acciones artísticas, estrechamente vinculadas con la naturaleza, están consideradas en la actualidad como la vanguardia del binomio Arte y Naturaleza y se reconocen por un especial respeto por el medio ambiente, mismo que lleva a los artistas a adoptar la propia práctica artística como una actividad pseudo espiritual. La precursora acción de la fotografía con algas nos sitúa frente a una metáfora del regreso a lo primario construida desde la propia sed individual de retorno al origen. Una práctica artística a la manera de una hierofanía íntima, que recupera una religiosidad pseudo-primitiva en la que la artista, empleando su propio cuerpo se integra en el medio natural en busca de una fusión íntima con el entorno.

La pose de los brazos, que se doblan hacia arriba sosteniendo una cinta, el tocado de algas que corona su cabeza y la falda acampanada recuerdan poderosamente a las Diosas de las serpientes en loza vidriada encontradas en el Palacio de Cnosos. Como apunta Zanetta, Mallo conocía de cerca los descubrimientos que había realizado el arqueólogo Arthur Evans en el yacimiento cretense (Mayayo, 2017, p. 87).

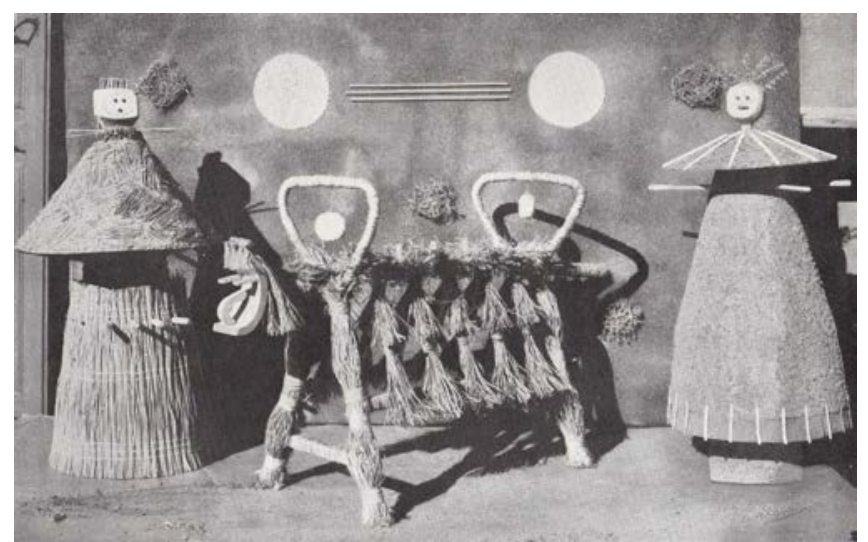

Figura 1. "Plástica escenográfica" para el ballet Clavileño (Madrid, 1936) de Maruja Mallo. (Fuente: Gómez de la Serna et al. 1942).

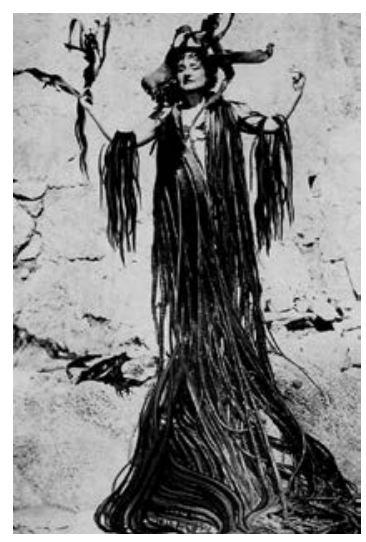

Figura 2. Maruja Mallo con manto de algas en las playas de Chile, ca. 1945. (Fuente: Archivo Maruja Mallo. Galería de Guillermo de Osma, Madrid).

Se trata por tanto de un temprano arte protoecológico que preconiza la simbiosis entre mujer, naturaleza y paisaje, y que plantea, de manera paralela, la colaboración entre los artistas y la naturaleza para romper las fronteras entre naturaleza y cultura. Mallo, se retrata aquí "como diosa de la fertilidad, como encarnación viviente de su universo mitológico" (Mayayo, 2017, p. 81) pero lo interesante "es que las instantáneas revelan, una vez más, un notable trabajo performativo" (Mayayo, 2017, p. 81) y que "sirven de registro de un proto-happening o happening privado, reflejando así la importancia que tuvieron este tipo de actos lúdicos y transgresores en la vanguardia española (Mayayo, 2017, p. 75).

\section{Miguel Hernández: un ruiseñor encaramado a los árboles}

Pablo Neruda describe cómo Miguel Hernández, durante su estancia en Madrid entre 1934 y 1936, realizaba acciones de forma improvisada para entrar en conexión con su origen rural. El poeta se encaramaba en lo alto de los árboles silbando como un ruiseñor (Fig. 3) o se pasaba el día entero subido a un árbol cargado de libros y manzanas.

Otras veces me hablaba del canto de los ruiseñores. El Levante español, de donde provenía, estaba cargado de naranjos en flor y de ruiseñores. Como en mi país no existe ese pájaro, ese sublime cantor, el loco de Miguel quería darme la más viva expresión plástica de su poderío. Se encaramaba a un árbol de la calle y, desde las más altas ramas, silbaba o trinaba como sus amados pájaros natales (Neruda, 1974, p. 164).

La acción se recoge aquí como muestra de la imperante necesidad del poeta de mantenerse en contacto con la naturaleza vegetal, aún y cuando su vida en la ciudad le obligara a llevar una vida más urbana.

\section{Vicente Escudero: bailando con árbol}

El bailarín y coreógrafo de flamenco español Vicente Escudero (Valladolid, 1888 - Barcelona, 1980) cuenta la anécdota de cómo, de niño, solía bailar sobre un árbol atravesado en el cauce del río Esgueva, que las personas utilizaban para pasar al otro lado: 
Allí tenía que luchar no sólo con la dificultad del sonido, mucho más pagado que en las chapas, sino también con el equilibrio, lo cual era para mí un nuevo aliciente, que me costó más de un chapuzón. El miedo a las mojaduras me hizo llegar a adquirir un equilibrio fantástico, que desde entonces conservo (Escudero, 1947, p. 41).

Prefería lo alternativo a las conservadoras academias de baile, inspirándose en cosas ajenas al baile, "bailar con el ruido del viento" (Escudero, 1947, p. 104), lo cual evidencia el proceso de aprendizaje del artista basado en la naturaleza.

La naturaleza me sirvió mucho de modelo. Trataba de imitar, en mis actitudes, las formas extrañas de los árboles y me hubiera gustado conseguir el ritmo gracioso con que una hoja al caer trata de burlar la ley de la gravedad. El baile tiene su ley de gravedad, la misma que yo quisiera poder burlar (Escudero, 1947, p. 105).

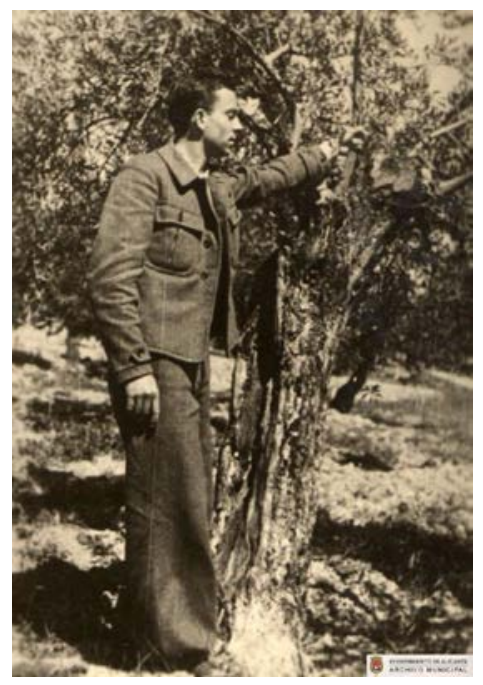

Figura 3. Miguel Hernández en el Frente Sur, 1937. Foto F. Sánchez. (Fuente: Archivo Municipal. Ayuntamiento de Alicante).

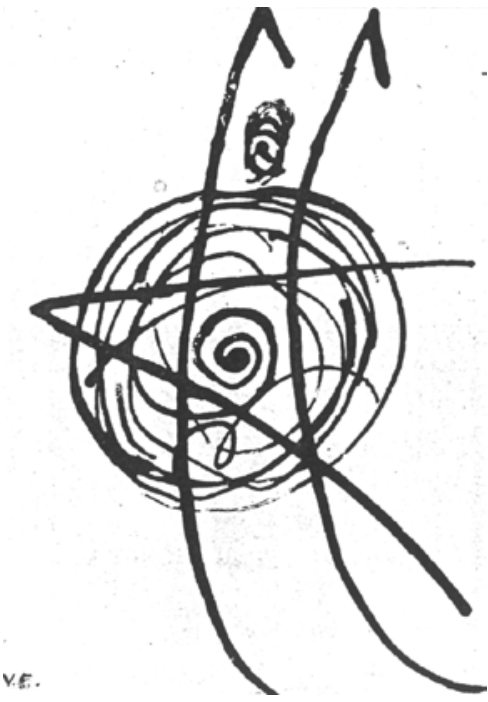

Figura 4. Flamenco racional. Dibujo original de Vicente Escudero. (Fuente: Escudero, 1947, p. 119).

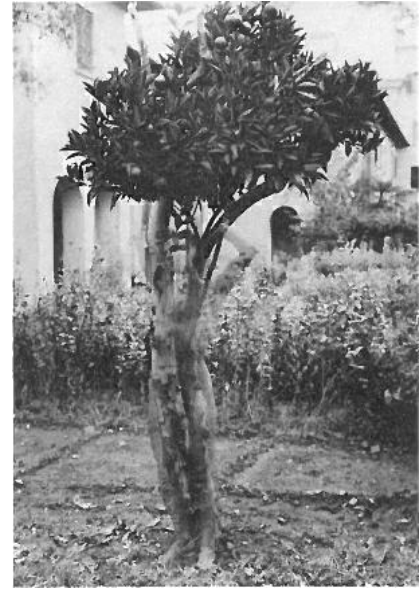

Figura 5. Fotografía de Gregorio Prieto junto a Eduardo Chicharro.

(Fuente: Fundación Gregorio Prieto)

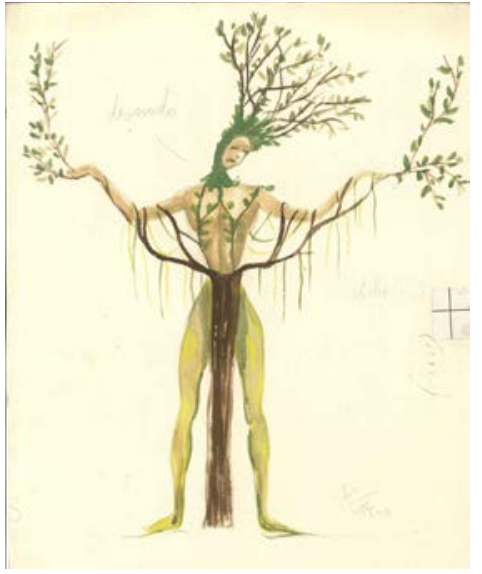

Figura 6. Figurín para la ópera La flauta mágica de Mozart, Madrid, 1945, de Vitín Cortezo. (Fuente: Museo Nacional del Teatro, Almagro).

En sus escritos incluía dibujos de sus movimientos (Fig. 4), fruto de su atracción por el mundo de la pintura. En ellos apunta que "en la época paleolítica los hombres lanzaban piedras al espacio y componían sus bailes con el ritmo producido por éstas al caer y chocar contra el suelo: "Ios hombres hacían bailar a las piedras y las piedras hacían bailar a los hombres" (Escudero, 1947, p. 118). El bailarín proponía bailar con "lo primero que tuviésemos a mano capaz de producir ruido" (Escudero, 1947, p. 123), incluso observando el movimiento de las ramas y las hojas de los árboles. 


\section{Gregorio Prieto: la metamorfosis vegetal}

El pintor Gregorio Prieto (Valdepeñas 1897-1992) construye una autobiografía personal a partir de un imaginario performativo, concibiendo imágenes concebidas por él y tomadas por amigos suyos. Se trata de fotografías en donde el artista aparece en escenas cargadas de surrealismo que destacan por su particular cercanía con la naturaleza vegetal. En alguna de las imágenes Prieto aparece transformándose en árbol (Fig. 5) siguiendo el mito de la metamorfosis de Dafne. Se observa aquí un concepto de hibridación humano-planta muy recurrente tanto en la pintura y la literatura como en la escultura.

\section{Vitín Cortezo: el árbol humano}

El interés que despertaron los materiales naturales como representación de lo auténtico se reflejaría también en el mundo del teatro a través de las aportaciones del figurinista y escenógrafo español Vitín Cortezo (Madrid, 1908-1978). Entre sus grandes aportaciones al vestuario teatral destacan el uso del color y la introducción de nuevos materiales, como el mimbre, las telas de saco y de tapicería "elementos muy innovadores para los años cuarenta" (Díaz De Quijano, 2012). "Yo personalmente aporté a la escenografía nacional, el mimbre, de tradición artesana muy esmerada, que por primera vez utilicé en El baile de los ladrones" (Peláez, 2012, p. 5). Sus figurines de bailarines desnudos con aplicaciones de ramas y hojas de árboles coinciden con un particular acercamiento a los materiales naturales. Los bocetos (Fig. 6) parecen corresponderse con los trajes que se utilizaron en la adaptación española de la ópera La flauta mágica de Mozart estrenada en 1945 en Madrid.

\section{Carmen Barradas: la música de las habichuelas}

Carmen Barradas (Montevideo, 1888-1963) pianista y compositora uruguaya, de padres españoles emigrantes, desarrolló un lenguaje musical propio muy innovador (Rueda, 2016). En 1915 viajó a Barcelona, junto con toda su familia. Fue autora de piezas como el tríptico Fabricación, Aserradero y Fundición, obra que compuso en España, en donde estrenaría tres obras más para piano, muy vanguardistas para la época. Este es el caso de Procesión Semana Santa, partitura fechada en 1927 y probablemente terminada en 1935.

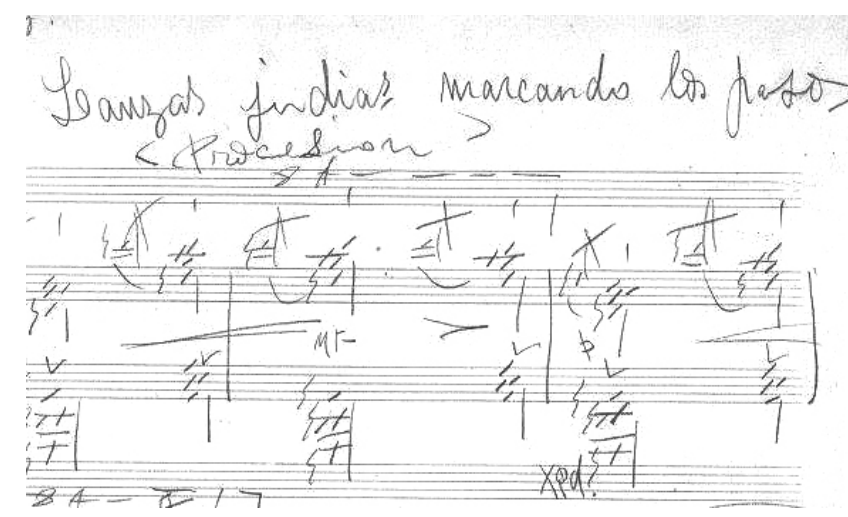

Figura 7. Partitura Procesión de Semana Santa en Hospitalet del Llobregat (1927-1935) de Carmen Barradas. (Fuente: Archivo Néffer Kröger)

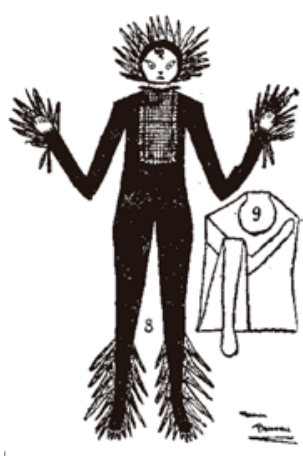

Figura 8. Traje del "gigante verde" (1924) de Carmen Barradas. (Fuente: Barradas, 16 de septiembre de 1924, p. 5).

En la página tres (Fig. 7) escribe "Lanzas judías marcando los pasos". Se puede intuir que las judías a las que se refiere son habichuelas secas que al caer al suelo hacen sonido. El elemento natural recupera sonidos de la época al paso de las procesiones, dando testimonio de cómo la religión ha absorbido las manifestaciones profanas que estaban relacionadas con los ciclos de las estaciones, de la naturaleza y con los periodos cíclicos de la agricultura.

Carmen también cosía muñecas (García-Sedas, 2017, p. 506). El 16 de septiembre de 1924 publica un cuento para confeccionar un muñeco (Fig. 8) en el que un sabio, Mr. Fornolt que trataba de crear un hombre artificial mediante substancias vegetales, entretejiendo ramas y troncos de árboles para formar una figura humana. Un día estalló una gran tormenta y una descarga eléctrica alcanzó al sabio que falleció. Los fluidos humanos del sabio fueron absorbidos por el muñeco sufriendo una metamorfosis:

[...] triunfó la materia vegetal en tal forma que echando raíces, creció un árbol con forma humana. Su color era verde, y en lo que formaba la cabeza, pie y mano brotaron unas hojas verdes y violadas. Cuando los campesinos tuvieron noticia del caso llamaron al extraño ser "el gigante verde" (Barradas, 16 de septiembre de 1924. p.5). 
Se desconoce el simbolismo que Barradas concede a la iconografía de este gigante verde, pero se perciben ciertas semejanzas formales entre esta figura y la foto de Maruja Mallo envuelta en algas. Una mística relación conecta las imágenes con la diosa Astarté por la posición frontal y los brazos formando un ángulo.

\section{Tórtola Valencia: la danza de la palmera}

A propósito de la innovadora utilización de materiales naturales en el teatro cabe resaltar las aportaciones de Carmen Tórtola Valencia (Sevilla, 1882-1955) quien recurría a la raphia (material natural procedente de la palmera) para el diseño de sus trajes. Destaca el carácter innovador que transmite dicho material en la imagen de la Danza Hilo-Hilo (Fig. 9) en la que se observa a la bailarina en acción. La recreación de una excéntrica personalidad se convierte así en una "performance identitaria compleja que articula el yo como un espacio ficticio, artificioso y disruptivo" (Cluá, 2015).

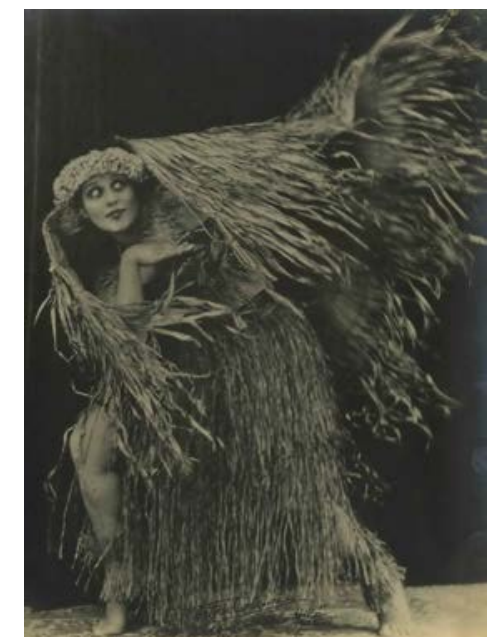

Figura 9. Danza Hilo-Hilo (1928) de Tórtola Valencia. (Fuente: Institut del Teatre. MAE).

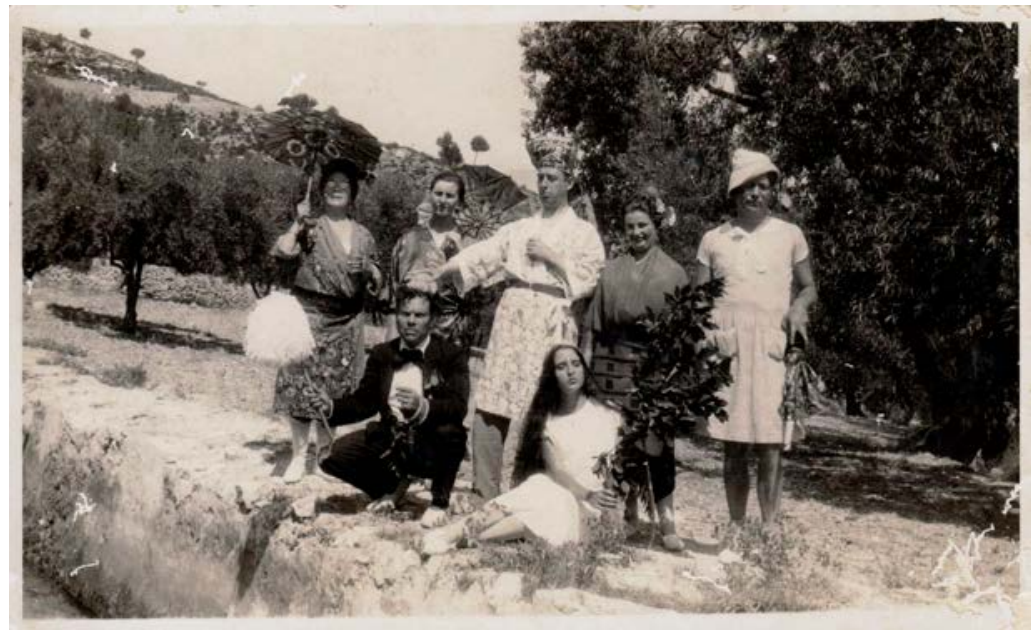

Figura 10. Bromas con Óscar en Aitana.

(Fuente: Fundación Caja Mediterráneo. Legado Emilio Varela. Ref. LEV 1-32).

\section{Emilio Varela: el arrebato vegetal}

El pintor Emilio Varela (Alicante, 1887) solía disfrutar de los paisajes del Valle de Guadalest y la Sierra de Aitana. El niño Vicentet le guía en los paseos. Varela recoge hierbas aromáticas y embriagado por un frenesí oloroso-vegetal, frota sobre su piel hierbas, metamorfoseándose con el paisaje. Esta acción tiene un fuerte componente performativo (Fig. 10) y se entiende como un acto de cercanía intensa con la naturaleza:

Vicentet conoce las flores y hierbas que todo lo ocupan: romeros, alhucemas, sabinas y tomillos, llenos de rocío, las plantas, los insectos, los pájaros y los pequeños reptiles que se esconden bajo las piedras y en las oquedades de las rocas. El pintor se sienta, coge plantas aromáticas, las aprieta con sus manos y las frota por su frente (Sánchez, 5 de enero de 2017).

\section{CONCLUSIONES}

Tradicionalmente la Naturaleza ha sido la gran maestra de las formas, no sólo en lo que se refiere a la vertiente matérico-orgánica de las creaciones artísticas, sino también en el mundo de la simbología y de la ficción. Su empleo en el ámbito artístico remite a conceptos vitales de transformación, aspectos que fueron rescatados por los artistas de la época, para despertar una nueva conciencia del ser humano frente al mundo. En todos estos casos, el elemento vegetal funciona como materia que reúne en sí todas las reminiscencias de la vida, convirtiéndose en una fuente inagotable de inspiración. El carácter de las imágenes descubre el valor de una fenomenología natural en la que se habla de exuberancia, de la capacidad de expandirse, de renacimiento y de sobrevivencia a pesar de las dificultades. Se recurre de manera trascendente a la acción o al camuflaje para conseguir la reproducción de sentimientos esenciales o la necesidad de progresar de manera creativa. Se trata de acciones innovadoras que plantean una metáfora analógica de supervivencia, una necesidad de expresión en donde las estrategias de mimetismo se convierten en acciones reivindicativas y precursoras en el ámbito del arte, que responden a la necesidad de renovación del imaginario no solo personal sino también colectivo. La recuperación de este tipo de expresiones para la historia del performance en España nos permite trazar un panorama del uso del cuerpo y la construcción de su expresividad en relación con la naturaleza, así como la preferencia por los elementos naturales como esencia de una verdad que a su vez describe la identidad de los artistas, poetas, músicos y bailarines. 


\section{FUENTES REFERENCIALES}

Abarca, I. (2012). Tiempo vegetal. Referencias botánicas en la escultura mexicana contemporánea (1990-2010). [Tesis doctoral]. Valencia: Editorial Universitat Politècnica de València. Recuperado de: https://riunet.upv.es/handle/10251/16876

Barradas, C. (16 de septiembre de 1924). La muñeca de España. De cómo nació el "Gigante verde" y llegó a ser ídolo de una princesita. Diario independiente Heraldo de Madrid.

Cluá, I. (2015). Excentricidad e hibridación: el caleidoscopio identitario de Tórtola Valencia. En Ferrús, B. y Del Pozo, A. (Coords.). Mosaico transatlántico: Escritoras, artistas e imaginarios (España-EEUU. 1830-1940). Valencia: Universitat de València.

Díaz De Quijano, F. (2012). Vitín Cortezo, la dignificación de lo canalla. Una exposición del CDN muestra el trabajo del escenógrafo y figurinista más prolífico de la posguerra. El Cultural. Edición digital (11 de mayo de 2012). Recuperado de: https://www.elcultural.com/noticiaimp.aspx?idnoticia=3161

Escudero, V. (1947). Mi baile. Barcelona: Montaner y Simón.

García-Sedas, P. (2017). Carmen Barradas: hilvanes y pentagramas. En iChum, Chum, Pim, Pam, Pum, Olé! Pioneros del arte Sonoro en España de Cervantes a las Vanguardias. Lucena: Weekend Proms.

Gómez de la Serna, R. et al. (1942). Maruja Mallo. 19 grabados en negro y 9 láminas en color. Buenos Aires: Losada.

Lucas, A. (2 de marzo de 2015). El arte de ser asombro. En Heterodoxas: Maruja Mallo. Recuperado de http://www.elmundo.es/cultura/2015/03/02/54f23cef268e3e343d8b457f.html

Mayayo, P. (enero de 2017). Maruja Mallo: el retrato fotográfico y la "invención de sí" en la vanguardia española. En Modos. Revista da História da arte. Campinas, 1(1), 70-89. Recuperado http://www.publionline.iar.unicamp.br/index.php/mod/article/view/730/690

Molina, M. (15 de noviembre de 2007). La performance española avant la lettre: Del Ramonismo al Postismo (1915-1945). Texto de la conferencia de Miguel Molina Alarcón. En Chámalle X. IV Xornadas de Arte de Acción da Facultade de Belas Artes da Pontevedra. Jornadas realizadas bajo la coordinación de Carlos Tejo. Un extracto de este texto se encuentra publicado en el catálogo AA.VV. Chámalle X. IV Xornadas de Arte de Acción da Facultade de Belas Artes. Servicio de Publicaciones de la Universidad de Vigo. Recuperado https://www.upv.es/intermedia/pages/laboratori/grup investigacio/textos/docs/miguel molina la performance avant.pdf

Neruda, P. (1974). Confieso que he vivido. Memorias. Barcelona: Seix Barral.

Neruda, P. (2002). Una casa en la arena. Santiago de chile: Pehuén Editores.

Peláez, A. (septiembre de 2012). Catálogo de Exposición homenaje. Vitín Cortezo. Escenógrafo y figurinista (1908-1978). Del auto sacramental a la vida perdularia. Teatro Valle-Inclán. Sala Francisco Nieva. Del 11 de mayo a 16 de junio de 2012. Recuperado de: http://cdn.mcu.es/wp-content/uploads/2012/09/cdn1112 23.pdf

Pérez de Ayala, J. (2009). Álbum/ Cronología. En Maruja Mallo. Catálogo de la exposición. Madrid: Sociedad estatal de conmemoraciones culturales.

Rueda, C. (2016). Carmen Barradas (1888-1963): su lenguaje musical innovador en el Uruguay. En Actas de las XIII Jornadas Interdisciplinarias de Investigación. Semana de la Música y la Musicología: El piano. Historia, didáctica e interpretación, (9-11 noviembre 2016). Universidad Católica Argentina. Facultad de Artes y Ciencias Musicales. Instituto de Investigación Musicológica "Carlos Vega", Buenos Aires. Recuperado de: http://bibliotecadigital.uca.edu.ar/repositorio/ponencias/carmen-barradas-lenguajemusical.pdf

Sánchez, M. (6 de enero de 2017). Emilio Varela y Oscar Esplá, historia de una amistad. Diario Información. Alicante. Recuperado de: https://www.diarioinformacion.com/cultura/2017/01/06/emilio-varela-oscar-espla-historia/1846215.html

Soler, J. (1980). La memoria literaria. Serie A fondo RTVE (1976-1981). Federico García Lorca visto por Maruja Mallo. Edición de Gonzalo Herralde (2017). 